\title{
İnsansız Hava Aracı ile Atmosferik Parçacık Örnekleme Sisteminin Dizaynı ve Yapımı
}

\author{
Design and Construction of Atmospheric Particle Sampling System by Unmanned Aerial \\ Vehicle
}

\author{
Bülent Oktay AKKOYUNLU ${ }^{1}$ (D) Ilker ORUC $^{2}$ (D) Emre ALPMAN $^{3}$ (D), \\ Barış DOĞAN $^{4}$ iD, Hakkı BALTACI ${ }^{5}$ iD
}

\author{
${ }^{I}$ Marmara Üniversitesi, Fen Edebiyat Fakültesi, Fizik Bölümü, Göztepe, İstanbul, Türkiye \\ ${ }^{2}$ Kırklareli Üniversitesi, Teknik Bilimler Meslek Yüksekokulu, Kırklareli, Türkiye \\ ${ }^{3}$ Marmara Üniversitesi, Mühendislik Fakültesi, Makine Mühendisliği Bölümü, Göztepe, İstanbul, Türkiye \\ ${ }^{4}$ Marmara Üniversitesi, Teknoloji Fakültesi, Mekatronik Mühendisliği Bölümü, Göztepe, İstanbul, Türkiye \\ ${ }^{5}$ Gebze Teknik Üniversitesi, Yer ve Deniz Bilimleri Enstitüsü, Gebze, Kocaeli, Türkiye
}

$\ddot{\mathbf{O} z}$

Atmosferik parçacıkların yerel, bölgesel ve küresel kaynaklarını belirlenmesini amaçlayan Pozitif Matriks Faktör Analizi, Potansiyel Kaynak Katkı Fonksiyonu, Kimyasal Kütle Dengesi gibi çeşitli nümerik modellerde kullanılan veriler, toplanan aerosol örneklerinden elde edilmektedir. $\mathrm{Bu}$ modellerin girdi kaynakları, bir bölgede toplanan parçacıkların analiz sonuçlarından elde edilen verilerdir. Atmosferik parçacıkların toplanması, genel olarak yer seviyesinde kurulan parçacık örnekleme sistemleri yoluyla gerçekleştirilmektedir. Yer seviyesinde örneklenen parçacıklar üzerinde yerel kaynakların katkısı, sınır ötesi uzun erimli yörüngeye sahip parçacıkların kaynaklarını belirleyen model çıktılarının sağlıklı değerlendirilmesini sınırlamaktadır. Bu çalışmada, model çalışmalarına katkı sağlayacak olan zemin seviyesinden farklı yüksekliklerde parçacık örnekleme yapabilecek insansız hava aracına yüksek taşınım verimliliğine sahip bir örnekleme sisteminin tasarlanması amaçlanmıştır. Üretime geçilmeden önce, örnekleme modülü ile ilgili akışa dayalı basınç ölçüm benzetim (simülasyon) çalışmaları gerçekleştirilmiştir. Parçacık örnekleme, insanlı hava araçlarında kullanılan tasarımlar incelenerek benzer tasarım insansız hava aracına uygulanmıştır. Model çıktılarında ve uygulamada, yüksek hızlarda insanlı hava araçları için tasarlanan örnekleme sistemlerinin, düşük hızlı insansız hava araçları için verimli olmadığı görülmüştür.

Anahtar Kelimeler: insansız hava aracı, parçacık örnekleme sistemi, giriş verimi, taşınım verimi

\section{Abstract}

The data, which are used on various numerical models such as Positive Matrix Factor Analysis, Potential Source Contribution Function and Chemical Mass Balance and aim to determine the local, regional and global sources of atmospheric particles, are obtained from the collected aerosol samples. The input sources of these models are the results obtained from the analysis of particles collected in a region. Collecting of atmospheric particles is generally carried out through particle sampling systems installed at ground level. Upon particles sampled at ground level, contribution of local sources limits the correct evaluation of the model outputs which determine the sources of the particles with cross-border long range trajectory. In this study, it has been aimed to design a sampling system which has a high efficiency of transportation for an unmanned air vehicle which can carry out particle sampling at various altitudes from ground level which contributes to modelling studies. Before passing to the production phase, simulation works of influx based pressure measurement with regard to the sampling module have been carried out. By observing the designs used in manned air vehicles, a similar design for particle sampling has been applied to unmanned air vehicles. In model outputs and applications, it has been seen that sampling systems designed for high-speed manned air vehicles are not efficient for low-speed unmanned air vehicles.

Keywords: unmanned aerial vehicle, particle sampling system, inlet efficiency, transport efficiency

\section{GİRIŞ}

Rüzgarlar ve atmosferik türbülanslarla Yeryüzünden atmosfere katılan aerosoller çok çeşitli doğal ve antropojenik kaynaklara sahiptir. Atmosferik parçacıkların taşınımı küresel ölçekte gerçekleşebilir. Bu taşınım sayesinde, Gobi Çölü'ndeki tozlar Kuzey Amerika'nın batı kıyılarına ve Sahra Çölü'ndeki tozlar Amerika Kıtası'na kadar ulaşabilir. Aerosoller gaz-partikül dönüşümüyle üretilirlerse uzun menzilli taşınımın olması beklenebilir. $\mathrm{Bu}$ dönüşüm için gerekli zaman ve bu süreçle üretilen partiküllerin diğerlerine göre küçük boyutta olması bu tür partiküllerin atmosferde kalma sürelerini uzatır [1]. 
Değişik kimyasal bileşen içeren atmosferik partiküller, pek çok çalışmanın konusu olmuştur. Doğru verilerin elde edilmesi bakımından, partiküler madde örnekleme çalışmalarında kullanılan teknik önem arz etmektedir. Çoğu aerosol ölçüm teknikleri başlıca iki kategoride değerlendirilebilir. İlki aerosollerin filtre gibi bir tabaka üzerinde toplanıp daha sonra genellikle örnekleme bölgesinden uzakta bir laboratuvarda ölçüm yapılmasıdır. İkincisi ise örnekleme gerçekleştirilirken yerinde ölçüm yapılmasıdır. Aerosol taşınımı, havanın ölçüm cihazına veya filtre yüzeyine bir taşıma hattı yoluyla çekilmesi ile gerçekleştirilir [2].

"NASA's Airborne Science Program" kapsamında bulut fiziği, kasırga ve atmosferik parçacıkları araştırma amaçlı yerinde analize uyumlu kargo uçakları ve sadece örnekleme için insansız hafif hava araçlar kullanılmaktadır [3]. Çalışmalar geniş coğrafik ölçeklerde gerçekleştirilebilir. Bulutlarda, kirletici kaynakları bilinen gaz sütunlarında, şehirlerde, arktik sislerde ve stratosferik volkanik bulutlardaki aerosol ölçüm ve analizleri hava araçları kullanılarak yapılmaktadır. Hava araçlarıyla yapılan ölçümler; hava kalitesi [4], stratosferik parçacıklar [5] ve iklim değişimi [6] gibi çeşitli alanların konusudur [7]. Pek çok ölçüm ve örnekleme tekniği; aerosollerin hava aracı dışındaki serbest hava akımından hava aracının kabininde bulunan ölçüm cihazlarına veya hava aracının kanat veya gövdesine monte edilmiş örnekleme ünitesine aktarmayı gerektirir. Hava türbülanslarının atmosferik aerosol ölçümleri üzerindeki etkisini inceleyen deneysel ve teorik çalışmalar gerçekleştirilmiştir [8-13]. Hava aracının gövde ve kanatlarındaki türbülanslar, aerosol konsantrasyonun lokal olarak artması veya azalması sonucunu doğurur. $\mathrm{Bu}$ konsantrasyon fark1, eylemsizlikleri nedeniyle parçacıkların stokes sayısının artması ile hava akış yörüngelerinden sapmasının bir sonucudur. $\mathrm{Bu}$ etkiler; hava aracının şekli, pervane büyüklüğü, örnekleme noktasının yeri, kanat kalınlığ 1 ve çapı gibi çeşitli etmenlere bağlıdır. Yüzde yüze yakın giriş verimi ve taşınım verimi elde etmeye yönelik bir örnekleme sisteminin tasarımı, bu alanda birçok araştırmanın konusudur [14-24].

Atmosferik parçacıkların toplanması, genel olarak yer seviyesinde kurulan parçacık örnekleme sistemleri yoluyla gerçekleştirilmektedir. Yer seviyesinde örneklenen parçacıklar üzerinde yerel kaynakların katkısı, sınır ötesi uzun erimli yörüngeye sahip parçacıkların kaynaklarını belirleyen model çıktılarının sağlıklı değerlendirilmesini sınırlamaktadır. Bu çalışmada; parçacıkların yüksekliğe bağlı örnekleme imkânı sağlayan insansız hava aracı ve ayrıca yer seviyesinde ve atmosferin değişik yüksekliklerinde yüzde yüze yakın giriş verimi ve taşınım verimi elde etmeye yönelik bir örnekleme sistemini tasarlanmış ve sistem test edilmiştir.

\section{MATERYAL VE YÖNTEM}

Numune toplamak için insansız hava aracı olarak özellikle havadan görüntü çekim işleri için geliştirilmiş bir model uçak (FPV (First Person View)) kullanılmıştır. Uzaktan kumanda ile kontrol edilen uçağa ayrıca otomatik uçuş sağlayan GPS (Global Positioning System) destekli uçuş kontrol kiti monte edilmiştir. Uçuş kontrol kitinin üzerinde barometre tabanlı dahili yükseklik ölçer bulunmakta olup, ayrıca hava akış hızının ölçümü (uçağın havadaki hızının hesabı) için ek algılayıcı bağlanmıştır. Ayrıca kitin sahip olduğu dahili hafızaya uçuş bilgileri (GPS koordinatları, yükseklik bilgileri, hava akış hızı bilgileri, vb.) kaydedilmiştir. Bu özellik sayesinde havadan elde edilecek numunelerin hangi şartlarda, hangi yükseklikte ve hangi bölgeden ölçüldüğü öğrenilmiştir. Uçuş kontrol kitine bağlanabilen telemetri (uzaktan ölçüm ve iletişim) modülü sayesinde uçak ile yer istasyonu canlı olarak iletişim kurabilmektedir. Yer istasyonunda bulunan bilgisayarda yüklü özel bir yazılım aracılığıyla (Mission Planner), harita üzerinden uçağa belirli bir rota tanımlanabilmektedir. Böylelikle uçak tanımlanan rotayı takip edebilmektedir. Aynı zamanda uçuş bilgileri, anında yerdeki bilgisayardan takip edilmiştir. Uçağın ön kısmında bulunan şeffaf kapaklı bölme içerisine uçuş kamerası monte edilmiştir. Kameranın AV (Audio Video) çıkışı OSD (on screen display) modülüne bağlanmıştır. OSD modülü uçuş kontrol kitinden aldığ1 uçuş bilgilerini video görüntüsü üzerine eklemektedir. OSD çıkışı yine uçağa takılacak video vericiye bağlanmıştır. Yer istasyonunda bulunan alıcılı ekran üzerinden uçağın uçuş görüntüsü ve uçuş bilgileri canlı olarak izlenmiştir.

Model uçak üzerine havadan numune almaya yarayacak özel tasarım kapaklı bir örnekleme sistemi eklenmiştir. Örnekleme sistemi fiziksel olarak bir boruya benzemektedir. Sistemin ön tarafinda, uzaktan verilecek komutla açılıp/kapanabilir motorlu bir kapak bulunmaktadır. McFarland vd. (1989) tarafindan geliştirilen tasarımda kullanılan teknik yaygın olarak kullanılan aerosol örnekleme tekniğidir [25] ve bu çalışmada tercih edilmiştir. Prob etrafında yerleştirilen koni (Shroud) serbest hava akışını yavaşlatmak amacıyla kullanılmıştır. Bu tasarımda prob ile koni arasında aralığın büyüklüğüne bağlı olarak serbest hava akış ile boşluktaki havanın hız oranı ayarlanabilir. Bu tekniği açıklamak amacıyla Şekil 1'de gösterilen çizim McFarland vd.'nin (1989) çalışmalarından alınmıştır [25]. 


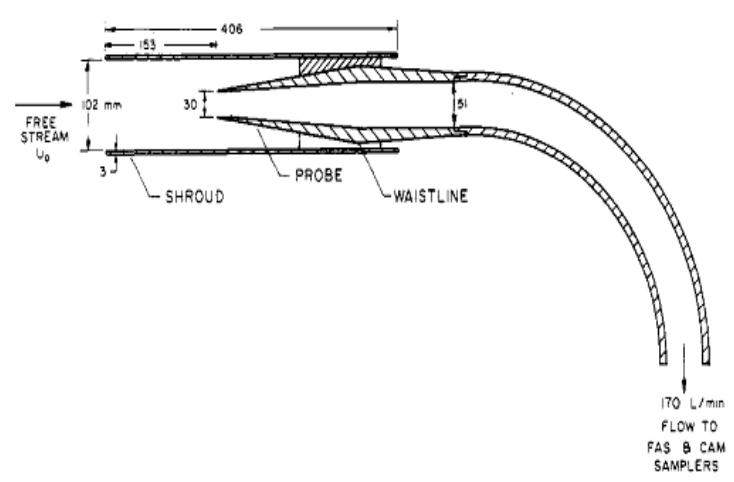

Şekil 1. Aerosol örnekleme sistemi

Örnekleme akımı bir pompa ile hava aracının içine taşınır. Prob nedeniyle sınırlandırılan akış alanı nedeniyle koninin içine giren havanın hızı, atmosferdeki serbest hava akış hızından daha yavaş̧ır. $\mathrm{Bu}$ tasarım yarı izokinetik örnekleme kabiliyetine sahiptir. Bu kapsamda aerosol örnekleme sistemleri için benimsenmiş standart bir tasarım veya yaklaşım mevcut değildir ve az sayıda hava aracında kullanılan örnekleme sistemi iyi hesap edilmiş verimliliğe sahiptir [25].

\section{BULGULAR VE TARTIŞMA}

\subsection{Sabit Kanatlı İnsansız Hava Aracı (IHA) Üretimi}

$\mathrm{Bu}$ çalışma kapsamında özellikle havadan görüntü çekim işleri için geliştirilmiş bir model uçak kiti alınarak birleştirilmiş, mekanik ve aviyonik bileşenlerinin montajı yapılmıştır. Uçak arkadan itişli tek motora ve yaklaşık 1,7 metre kanat genişliğine sahiptir. FPV olarak da isimlendirilen bu model tipinin seçilmesinin en önemli nedeni, havadan numune alınması sırasında hava akımını olumsuz yönde etkileyecek pervane gibi bileşenlerin uçağın en arkasında olmasıdır. Uçağın üst tarafında, parçacık örnekleme modülünün yerleştirilebilmesi için düz ve geniș bir alanı vardır. Ayrıca uçağın uzun süre havada süzülebilmesi için geniş kanatlara sahip olması ve oldukça hafif olması da diğer tercih sebeplerindendir. Hafiflik özelliği, uçak gövdesinin yapımı için büyük oranda EPO (Expanded Poly Olefin) ve yer yer karbonfiber ile ahşap malzemelerin kullanılmasından ileri gelir. Uçak taşıyacağı yükün ağırlı̆̆ 1 ve kullanılacak batarya kapasitesine göre 1-2 saat havada kalabilmektedir.

Model uçak montaj için kutusundan çıkarıldığında, gövdesi iki parça kabuk halinde, kanatlar ise ayrı olarak bulunmaktaydı. İlk önce motorun uçağa bağlantısını sağlayacak ahşap parça tasarlanmış ve kesilmiştir. Motor, bu parça üzerine vidalanarak gövdeye monte edilmiştir. Motorun elektrik kabloları, ızgara desenli makron içinden geçirilmiş ve motor sürücüsü (ESC) ile bağlantısı sağlanmıştır. Uçağın kanatçık yönlendirme servoları kanatlara yerleştirilerek, elektriksel bağlantıları yapılmıştır. Sonrasında uçağın havadayken fark edilmesini sağlayan çakar lambaların montajı yapılmıştır. Uçak yerden kumanda edilirken fark edilebilmesi için lambalardan biri uçağın ön-alt tarafina, uçak havayken diğer araçlar tarafindan fark edilebilmesi için diğer lamba uçağın arka-üst tarafına yerleştirilmiştir. Şekil 2'de uçağın gövde arkasına bağlanmış motor, 1zgara makron içindeki güç kabloları, arka-üst çakar lamba ve servo bağlantı kabloları görülmektedir. Çakar lambaların elektronik sürücüsü gövdenin orta-alt tarafina monte edilmiştir.

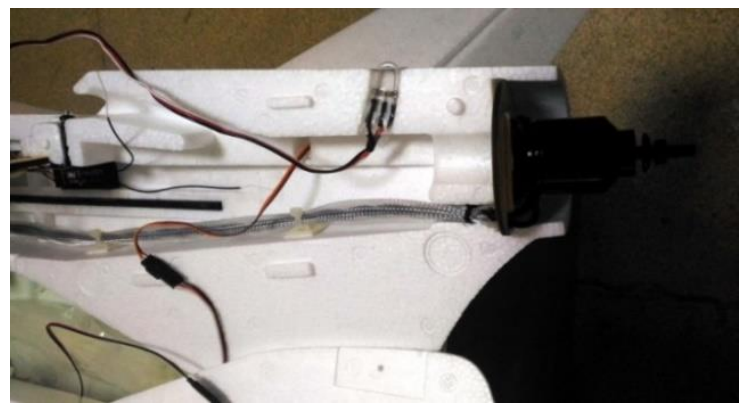

Şekil 2. Uçak gövdesinin birleștirilmemiş haldeki arka tarafı görüntüsü

Uçağın hareketini sağlayan itki sistemine ait güç elektroniği bağlantıları tamamlandıktan sonra, uçuş kontrol kart1 (aviyonik) ve çevre birimlerinin bağlantıları yapılmıştır. Uçuş kontrol kartı üzerinde 9 serbestlik dereceli açı ölçme ünitesi (SDAÖÜ) ile barometre bulunmaktadır. 9 SDAÖÜ; 3'er eksen ivme, manyetometre (pusula) ve gyro algilayıc1lardan oluşmakta ve aracın yer çekimine göre yönü, eğimi gibi verilerin ölçülmesinde kullanılmaktadır. Hava basıncındaki değişim barometre ile ölçülerek uçan aracın yüksekliği hesaplanmaktadır. Uçuş kontrol kartı, uçağın otonom uçuş ve otomatik dengeleme (stabilizasyon) gibi ileri seviye işlevleri yürütmektedir. Uçuş kontrol kartı, uçağın gövdesinin iç orta bölümüne, ahșap platform üzerine Şekil 3 'te görüldüğü gibi monte edilmiştir.

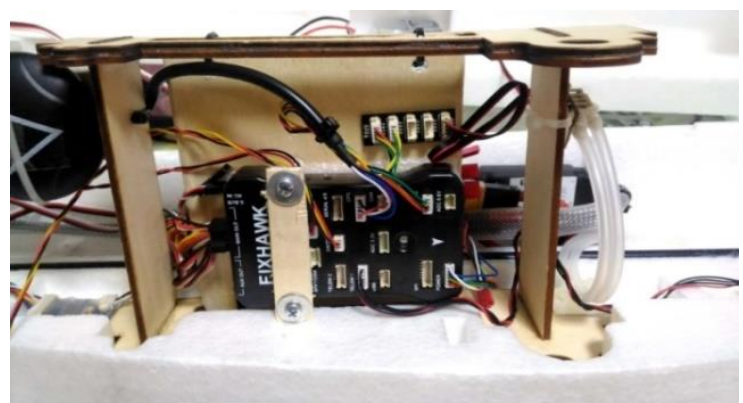

Şekil 3. Uçuş kontrol kartının ahşap platform üzerine montajının yapılmış halinin üstten görüntüsü

Uçuş kontrol kartı bağlantıları yapıldıktan sonra kabuk şeklinde iki parça halinde üretilmiş olan uçak gövdesi özel bir yapıştırıcı ile birleştirilerek son halini almıştır. Uçuş kontrol kartının ileri seviye işlevleri yürütebilmesi için çevre birimlere ihtiyacı vardır. Uçak ile yer istasyonu arası veri iletişimini kuran telemetri modülü, uçağın havadaki hızını ölçen pitot tüpü, uçağın 
dünya üzerindeki konumunu belirleyen GPS ve pusula modülü, güç ve ölçüm modülü bu çevre birimlerine örnek olarak verilebilir. Uçağın havadaki ilerleme hızının ölçümü, uçağın havada kalabilmesi için oldukça önemli bir işlemdir. Bu ölçümün yapılabilmesi için pitot tüpü olarak adlandırılan aparat ile basınç farkını ölçen algılayıcı kullanılmıştır. Pitot tüpü ile basınç algılayıcı arası bağlantı hortumlar ile sağlanmaktadır. Hava hızının doğru ölçülebilmesi için pitot tüpü, uçağın üzerindeki en düzgün hava akışının olduğu burun tarafına yerleştirilmiştir. Şekil 4'te uçağın sağ-ön tarafinda yer alan ve normalde üzeri koruma amaçlı mavi örtü ile kaplı olan çubuk pitot tüpü ve pitot tüpü ile basınç algılayıcısı arasında döşenmiş olan borular görülmektedir.
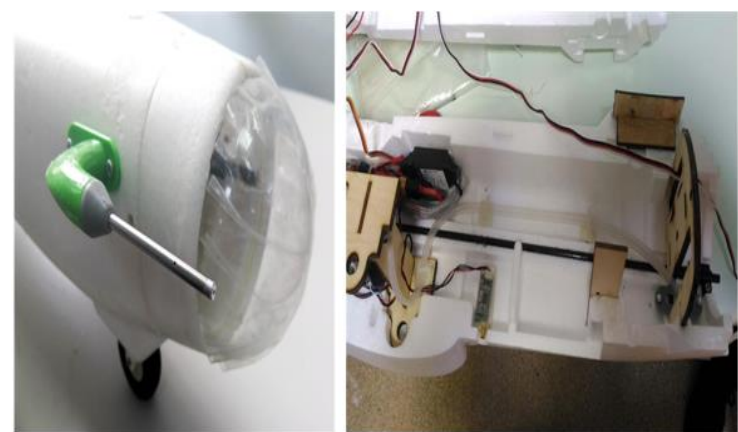

Şekil 4. Solda, uçağın sağ-ön tarafinda yer alan pitot tüpü; sağda, pitot tüpü ile basınç algılayıcı arasındaki hava hortumları görüntüsü

Uçak itki sistemi, uçuş kontrol kartı, uzaktan kumanda modülü ve çevre bileşenlerinin montajları ile bağlantıları tamamlandıktan sonra özel bir yapıştırıcı kullanılarak, gövdeye ait kabuklar birleştirilmiştir. Daha sonra model uçak üzerine havadan numune almaya yarayacak özel tasarım kapaklı bir örnekleme sistemi eklenmiştir. Bunun sonucunda uçak uçuşa hazır hale gelmiştir. Şekil 5'te parçacık örnekleme modülü ile birlikte uçuşa hazır haldeki uçağın görüntüsü verilmiştir.

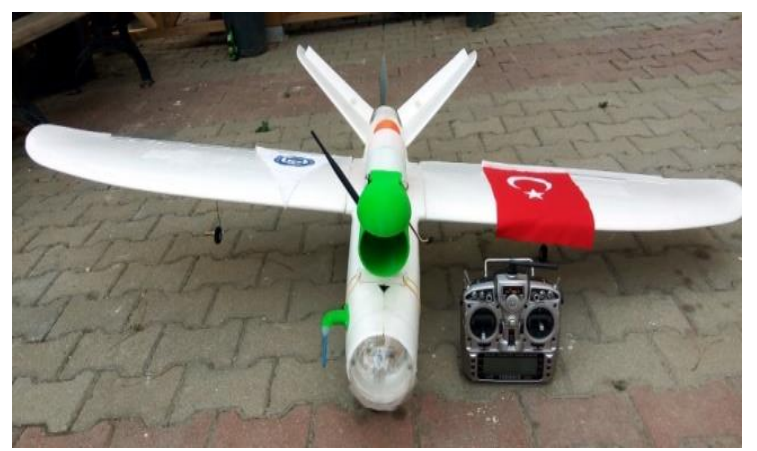

Şekil 5. Uçuşa hazır uçağın görüntüsü

\subsection{Yer İstasyonu Kurulumu}

Hava araçlarının irtifa, havadaki hız, tüketilen enerji, kalan enerji, coğrafi konum, kuzey yönüyle yapılan açı vb. uçuş bilgilerini canlı olarak görüntülemek ve rota planlayabilmek için yer istasyonu kullanılır. Yer istasyonu temel olarak bir haberleşme (telemetri) modülü, anten, bilgisayar (veya tablet, cep telefonu, vb.) ve uçuş kontrol kartı ile uyumlu özel bir yazılımdan oluşur. Çalışma kapsamında üretilen sabit kanatlı İHA için bir yer istasyonu kurulmuştur. Şekil 6'da görülmekte olan yer istasyonunda bir adet telemetri modülü, $3 \mathrm{dbi}$ anten ve Mission Planner yazılımı yüklü laptop kullanılmıştır.

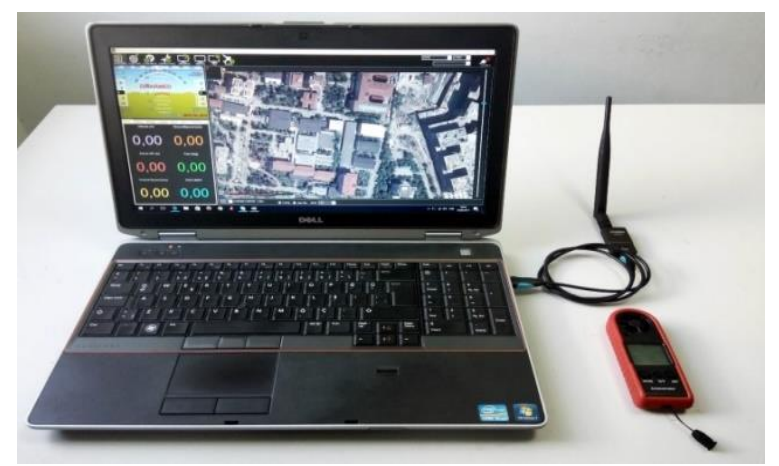

Şekil 6. İHA için kurulan yer istasyonu görüntüsü

Mission Planner yazılımı, İHA üzerindeki uçuş kontrol kartının kendi telemetri modülü ile yer istasyonuna gönderdiği bilgileri görüntülemektedir. Böylece hava aracının konumu bilgisayar ekranı üzerindeki harita üzerinde canlı olarak görülebilir. Ayrıca Mission Planner yazılımı; uçuş kontrol kartına gömülü sistem yazılımı yüklemek, İHA için rota planlaması yapmak, İHA'nın uçuş kontrol parametrelerini görüntülemek/değiştirmek için de kullanılır. Yazılımın Android işletim sistemini çalıştıran cep telefonu ve tablet gibi mobil cihazlarda çalışan DroidPlanner ve Tower isimli versiyonları da vardır. Uçuş yapılacak bölgenin rüzgar hızı, hava sıcaklığı ve nem oranı gibi atmosferik bilgileri ölçmek için ise anemometre kullanılmıştır.

\subsection{Parçacık Örnekleme Modülü Tasarımı, Akış Benzetimleri ve Üretimi}

İHA uçarken havadaki parçacık örneklerini toplamak üzere özel bir modül tasarlanmıştır. Tasarımda havadaki parçacıkları toplayan bir dış silindir içerisinde 4 adet küçük kanatçıklar ile sonlara doğru tutturulmuş bir iç silindir kullanılmıştır. Dış silindir içine giren havanın, silindirin iç çeperlerine doğru türbülanslıdır. Bu nedenle iç silindir, içeri alınan havanın türbülanssız olan orta bölümü ayırmak için kullanılmaktadır. İç silindirin dar olan girişinin giderek genişlemesi, iç silindir içine alınan havanın akış hızını düşürmektedir. Böylelikle hem iç silindir içinde oluşabilecek türbülansların önlenmesi hem de içeri alınan havanın iç silindirin sonlarına doğru konumlanmış filtre kağıdına daha düşük bir hızda çarparak parçacıklarını bırakması hedeflenmiştir. Diş silindirin önüne bir servo motora bağlı kapak yerleştirilmiş, böylece sadece istenilen irtifa veya bölgeye ulaşıldığında kapak açılarak parçacık örneklemenin başlaması sağlanmıştır. İç silindirin filtre kağıdından hemen önceki ve sonraki bölümünde akış hızını ölçebilmek için diferansiyel basınç sensörü bağlantı noktaları oluşturulmuştur. İç 
silindirden akan havanın hızı arttıkça filtre önü ile filtre sonrasındaki basınç farkı da orantılı olarak artacaktır. İç silindirin sonuna bal peteği desenli borular yerleştirilerek filtreyi terk eden havanın akış formu da düzeltilmeye çalışılmıştır.

\subsection{CFD Model Çalışması}

Tasarımdan üretime geçilmeden önce örnekleme modülü ile ilgili akışa dayalı basınç ölçüm benzetim (simülasyon) çalışmaları yapılmış̦tır. Şekil 7'de örnekleme modülünün tam ortasından geçen bir yüzey üzerinde elde edilen basınç ve hız tahminleri görülmektedir. Benzetim çalışmasında yaklaşık bir milyon elemana sahip yapısız bir ağ oluşturulmuştur. Rüzgar hızı $10 \mathrm{~m} / \mathrm{s}$ kabul edilmiş ve çözümlerde "RNG k-epsilon türbülans modeli” kullanılmıştır.

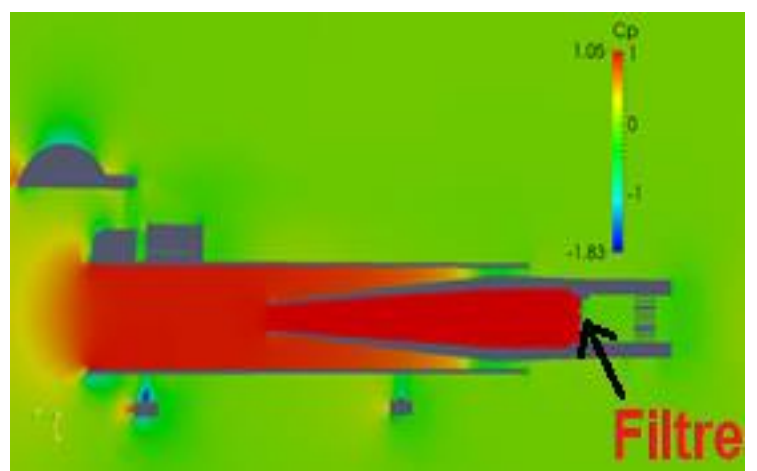

Şekil 7. Rüzgar hızı $10 \mathrm{~m} / \mathrm{s}$ iken parçacık örnekleme modülündeki basınç katsayısı dağılımı görüntüsü

Şekil 7'de yeşil bölgeler basınç katsayısının sıfir olduğunu ve atmosfer basıncını, kırmızı renge giden bölgeler basınç katsayısının pozitif olduğunu ve basıncın atmosfer basıncından daha yüksek olduğunu, mavi renge giden bölgeler ise basınç katsayısının negatif olduğunu ve basıncin atmosfer basıncından daha düşük olduğunu göstermektedir. Buna göre içteki silindirin sonuna konmuş filtrenin önünde neredeyse tüm yapı içerisine yayılan ve özellikle iç silindir içerisinde etkisini gösteren bir yüksek basınç alanı oluştuğu görülebilmektedir. Bu yüksek basınç alanının oluşması örnekleme sistemi içine giren havanın rüzgar yönünün tersine doğru geri itileceği sonucunu çıkarmaktadır.

Şekil 8'de ise parçacık örnekleme modülü yüzeylerindeki hız dağılımları ve hız vektörleri görülmektedir. Şekil 7'deki basınç dağılımları ardından beklendiği gibi örnekleme sistemi içerisindeki akış hızı dışarıya göre daha düşüktür. Ancak burada en dikkat çeken unsur, filtrenin bulunduğu iç silindir içerisindeki akış hızının oldukça düşük olmasıdır. Bu durum da havanın filtreye doğru gitmek yerine kenarlardan dış silindirin (toplayıcının) dışına doğru kaçtığı anlamına gelmektedir.

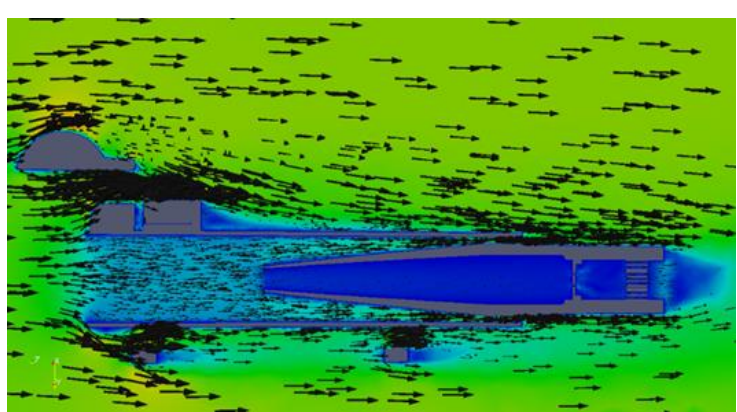

Şekil 8. Rüzgar hızı 10m/s iken parçacık örnekleme modülündeki hava akış hızı dağılımı görüntüsü

Şekil 8'deki vektör oklarının büyüklüğü, o noktadaki hızın büyüklüğü ile orantılıdır. Bu şekilden havanın iç silindirin içine doğru gitmek yerine kenarlarından toplayıcının dışına doğru kaçtığını görülebilmektedir. $\mathrm{Bu}$ nedenle parçacık örnekleme modülünün en arka tarafına bir fan yerleştirilerek filtre kağıdı arkasında bir negatif basınç bölgesi oluşturulmuştur. Böylesi bir fan ekleme ihtiyacı olup olmadığına deneme örnekleri alındıktan sonra karar verilecektir. Proje kapsamında tasarım ve benzetim çalışmalarından sonra üretimi yapılmış olan parçacık örnekleme modülünün yandan ve önden görünümü Şekil 9'da görüldüğü gibidir.

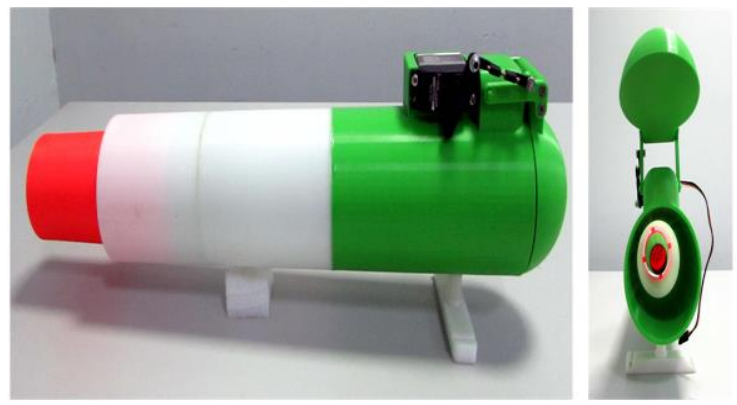

Şekil 9. Parçacık örnekleme modülünün yandan (kapak kapalı) ve önden (kapak açık) görüntüsü

\section{SONUÇLAR}

Çalışma kapsamında parçacıkların yüksekliğe bağlı örnekleme imkânını sağlayan insansız hava aracı tasarlanmış, yüksekliğe bağlı atmosferik parçacık örnekleme sistemi geliştirilmiş ve üretimi gerçekleştirilmiştir. Örnekleme sisteminin içindeki silindirin son kısmına konulmuş filtrenin önünde yüksek basınç alanı oluştuğu görülmüştür. Bu yüksek basınç alanının, hemen hemen tüm yapı içerisine yayılmış ve özellikle iç silindir içerisinde etkisini gösteren bir basınç alanı olduğu gözlenmiştir. Örnekleme sistemi içine giren havanın bu yüksek basınç alanının varlığı ile rüzgar yönünün tersine doğru geri itildiği belirlenmiştir. Filtrenin yer aldığ iç silindir içerisindeki akış hızının oldukça düşük olduğu gözlenmiş, bu durumdan dolayı havanın filtreye doğru gitmek yerine kenarlardan dış silindirin (toplayıcının) dışına doğru kaçtığı belirlenmiştir. Kısacası ilk benzetim çalışması sonuçları, tasarlanan örnekleme sisteminin geometrisinin, havayı filtreye doğru çekme konusunda çok başarılı olamadığını göstermektedir. 
Örnekleme aparatının uçağın aerodinamiğinde uçuşu zorlaştırıcı derecede etki yaptığı belirlenmiştir. Parçacık örnekleme modülünün düşük hılarda örnekleme yapacak şekilde tasarımında değişikliğe ihtiyaç vardır. Hava giriş yerinin dar giriş yerine daha geniş tutulması ve örnekleme modülünün arka tarafına bir fan yerleştirilmesinin sorunu çözeceği öngörülmektedir. Örnekleme modülünün gövdenin içine yerleştirilmesi ve hava girişi için hava akış kanalının gövde altından açılması uçağın aerodinamiğinde uçuşu zorlayan etkileri azaltacaktır.

\section{TEŞEKKÜR}

Bu çalışma Marmara Üniversitesi Bilimsel Araştırma Projeleri Birimi (BAPKO) tarafindan FEN-C-DRP100615-0275 numaralı proje kapsamında desteklenmiştir.

\section{KAYNAKLAR}

[1] Wallace, J.M., \& Hobbs, P.V. (2006). Atmospheric Science: An Introductory Survey, 2.Bask1, Elsevier Inc., San Diego, CA, USA. s. 153-207.

[2] Kulkarni, P., Baron, P.A., \& Willeke, K. (2011). Introduction to Aerosol Characterization. In: Aerosol Measurement: Principles, Techniques, and Applications, P. Kulkarni, P.A. Baron, \& K. Willeke (ed.), 3.Baskı, John Wiley \& Sons, Inc. Hoboken, New Jersey, USA, s. 3-13.

[3] NASA, http://www.nasa.gov/topics/earth/features/air_sci _missions_2012.html, (January, 2017).

[4] Fehsenfeld, F., Hastie D., Chow J., \& Solomon, P. (2004). Particle and gas measurements. In: Particulate Matter Science for Policy Makers: A NARSTO Assessment, P.H. McMurry, M.F. Shepherd, \& J.S. Vickery (ed.), Cambridge University Press, Cambridge, UK, s. 159-189.

[5] Hamill, P., Brogniez, C., Thomason, L., Deshler, T., Antuña, J., Baumgardner, D., Bevilacqua, R., Brock, C., David, C., Fussen, D., Hervig, M., Hostettler, C.A., Lee, S.-H., Mergenthaler, J., Osborn, M. T., Raga, G., Reeves, J. M., Rosen, J., \& Wilson, J. C. (2006). Instrument Descriptions, L. Thomason \& Th. Peter (ed.), SPARC Assessment of Stratospheric Aerosol Properties (ASAP), 77-106, SPARC Report No. 4, World Climate Research Programme-124 (WMO /TD1295).

[6] CCSP, (2009). Atmospheric Aerosol Properties and Climate Impacts, Synthesis and Assessment Product 2.3 Report by the U.S. Climate Change Science Program and the Subcommittee on Global Change Research, M. Chin, R.A. Kahn, \& S.E. Schwartz (ed.), Washington: NASA.

[7] Wilson J.C. \& Jonsson H. (2011). Measurement of Cloud and Aerosol Particles from Aircraft. In: Aerosol Measurement: Principles, Techniques, and Applications, P. Kulkarni, P.A. Baron, \& K. Willeke (ed.), 3.Baskı, John Wiley \& Sons, Inc. Hoboken, New Jersey, USA, pp.655-665.
[8] Beard, K.V. (1983). Reorientation of hydrometeors in aircraft accelerated flow. Journal of Climate and Applied Meteorology, 22, 1961-1963.

[9] Baumgardner, D. (1984). The effects of airflow distortion on aircraft measurement: A workshop summary. Bulletin of the American Meteorological Society, 65, 1212-1213.

[10] King, W.D. (1984). Air flow and particle trajectories around aircraft fuselages. I: Theory. Journal of Atmospheric and Oceanic Technology, 1(1), 5-13.

[11] King, W.D. (1986). Air flow and particle trajectories around aircraft fuselages. IV: Orientation of ice crystals. Journal of Atmospheric and Oceanic Technology, 3(3), 433439.

[12] MacPherson, J.I., \& Baumgardner, D. (1988). Airflow about King Air Wingtip-Mounted cloud particle measurement probes. Journal of Atmospheric and Oceanic Technology, 5(2), 259273.

[13] Twohy, C.H., \& Rogers, D. (1993). Airflow and water-drop trajectories at instrument sampling points around the Beechcraft King Air and Lockheed Electra. Journal of Atmospheric and Oceanic Technology, 10(4), 566-578.

[14] Pena, J.A., Norman, J.M., \& Thomson, D.W. (1977). Isokinetic sampler for continuous airborne aerosol measurements. Journal of the Air Pollution Control Association, 27(4), 337-341.

[15] Noone, K.J., Ogren J.A., Heintzenberg, J., Charlson, R.J., \& Covert, D.S., (1988). Design and calibration of a counterflow virtual impactor for sampling of atmospheric fog and cloud droplets. Aerosol Science and Technology, 8(3), 235-244.

[16] Huebert, B.J., Lee, G., \& Warren, W.L. (1990). Airborne aerosol inlet passing efficiency measurement. Journal of Geophysical Research, 95(D10), 16369-16381.

[17] Jonsson, H.H., Wilson, J.C., Brock, C.A., Knollenberg, R.G., Newton, T., Dye, J.E., Baumgardner, D., Borrmann, S., Ferry, G.V., Pueschel, R., Woods, D.C., \& Pitts, M. C. (1995). Performance of a focused cavity aerosol spectrometer for measurements in the stratosphere of particle size in the 0.06-2.0- $\mu \mathrm{m}$-diameter range. Journal of Atmospheric and Oceanic Technology, 12(1), 115-129.

[18] Twohy, C.H. (1998). Model calculations and wind tunnel testing of an isokinetic shroud for highspeed sampling. Aerosol Science and Technology, 29(4), 261-280.

[19] Laucks, M.L., \& Twohy, C.H. (1998). Sizedependent collection efficiency of an airborne counter flow virtual impactor. Aerosol Science and Technology, 28(1), 40-61.

[20] Hermann, M., Stratmann, F., Wilck, M., \& Wiedensohler, A. (2001). Sampling characteristics of an aircraft-borne aerosol inlet 
system. Journal of Atmospheric and Oceanic Technology, 18(1), 7-19.

[21] Twohy, C.H., Strapp, J.W., \& Wendisch, M. (2003). Performance of a counterflow virtual impactor in the NASA icing research tunnel. Journal of Atmospheric and Oceanic Technology, 20(6), 781-790.

[22] Huebert, B.J., Howell, S.G., Covert, D., Bertram, T., Clarke, A., Anderson, J.R. , Lafleur, B.G., Seebaugh, W.R., Wilson, J.C., Gesler, D., Blomquist, B. \& Fox, J. (2004). PELTI: Measuring the passing efficiency of an airborne low turbulence aerosol inlet. Aerosol Science and Technology, 38(8), 803-826.
[23] Hegg, D.A., Covert, D.S., Jonsson, H., \& Covert, P.A. (2005). Determination of the transmission efficiency of an aircraft aerosol inlet. Aerosol Science and Technology, 39(10), 966-971.

[24] Chen, J., Conant, W.C., Rissman, T.A., Flagan, R.C., \& Seinfeld, J.H. (2005). Effect of angle of attack on the performance of an airborne counterflow virtual impactor. Aerosol Science and Technology, 39(6), 485-491.

[25] McFarland, A.R., Ortiz, C.A., Moore, M.E., DeOtte, Jr., R.E., \& Somasundaram, S. (1989). A shrouded aerosol sampling probe. Environmental Science \& Technology, 23(12), 1487-1492. 